\title{
The Academic Performance of Pupils with Autism and Intellectual Impairment in Special and Inclusive Primary Schools in Tanzania
}

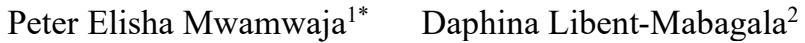 \\ 1.Lecturer, Faculty of Education, Teofilo Kisanji University \\ 2.Lecturer, Faculty of Education, The Open University of Tanzania
}

\begin{abstract}
In Tanzania, several initiatives have been made in establishment of special and inclusive schools, mostly in urban areas. The government and community at large show commitments in addressing the needs of pupils with autism and intellectual impairment including the curriculum for learners with mental disabilities of 2008 in primary schools. The question that arises is whether pupils with autism and intellectual impairment in special and inclusive classrooms in Tanzania perform well academically. It is on this premise that this study was based. The study intended to assess academic performance of pupils with autism and intellectual impairment in special and inclusive classrooms in Tanzania. The study employed mixed methods research approach with a quasimixed design. Data were collected using pupil's assessment tool. Five inclusive primary schools were purposively chosen from two regions in Tanzania Mainland. Fifty pupils with autism and intellectual impairment participated in the study. Descriptive and inferential statistics were computed. The paired t-test was used to analyse the counting skills of the pupils, while the differences in their academic performance was established by the use of chi-square test. The findings revealed that pupils with intellectual impairment performed relatively higher in all selected tasks (number, communication and vocational skills) comparing to pupils with autism. As such, some deliberate efforts are required for enabling them to acquire competencies as outlined in the curriculum for primary school pupils in Tanzania.

Keywords: Academic performance, Autism, Intellectual impairment, Special and inclusive schools, Tanzania

DOI: $10.7176 / \mathrm{JEP} / 11-20-07$

Publication date:July $31^{\text {st }} 2020$

\section{Introduction}

Tanzania as a signatory of the international agreements on provision of education for all persons is obligated to ensure her citizens acquire at least basic education (Tungaraza, 1994; United Nations, 2007). Implicitly, the education policy statement indicates that people with disabilities have the same rights as everyone else (URT, 2014). It is of expectation that after completion of primary education cycle pupils with autism and intellectual impairment should have the following competencies: to be able to socialize with people of different status, to live independently, to be employed or self-employed, to develop academically and finally to recognize, preserve and utilize the environment sustainably. This should not be taken for granted, that all pupils enrolled in primary schools learn and perform equally. Several studies (such as, Odom, Brown, Frey, Karasu, Smith-Canter, \& Strain, 2003; Asonitou, Koutsouki, Kourtessis \& Charitou, 2012) indicate positive correlation between cognitive failures and academic performance. These studies determined that pupils with autism and intellectual impairment are faced with significant problems in cognitive functions and lower scores in attention and learning (reading, writing, and spelling) compared with their normal peers.
\end{abstract}

\section{Background to the Study}

One of the major aims of the Tanzania's education system is to enable learners to acquire various life skills for their own survival and lead a decent life. Bloom, Canning and Chan (2006) pointed out that, education is widely accepted as a key instrument for promoting economic growth in many nations. Since independence, the Government of Tanzania has recognised the central role of education in achieving the overall development goal of improving the quality of life of Tanzanians through economic growth and poverty reduction (URT, 2006; Woods, 2007).

On the historical account, pupils with autism spectrum disorder and intellectual impairment have not benefited well in education (Cole\& Meyer, 1991). They have been in inclusive schools with large class sizes. Some parents, teachers, and educational authorities had fear that such inclusion could affect academic performance of pupils without disabilities. This is not exclusively true, as Cole, Waldron and Majd (2004) and Dessemontet and Bless (2013) found that the inclusion of pupils with autism and intellectual impairment in primary regular education classrooms with support is not detrimental to the academic progress of students without disability. Such findings are of critical importance, as it could help to alleviate fears among parents, teachers, and educational authorities, and might support efforts made to develop inclusive practices for children with intellectual impairment.

Pupils with autism are those with autism spectrum disorder, which means pupils with deficits in developing 
social and communication skills (National Autistic Center - Kenya, 2009). They have difficulty with communication and social relationships; display behaviors not typical of their peers; and respond to sensory stimuli by screaming or reacting strongly to light, sound, or motion (Sicile-Kira, 2004; Hart \&Whalon, 2011).Intellectual impairment is a term used when a person has certain limitations in mental functioning and in skills such as communicating, taking care of him or herself, and social skills. Pupils with intellectual impairment have difficulty remembering information and have trouble attending to relevant features of learning task and so may focus on distracting irrelevant stimuli (Luckasson,Borthwick-Duffy, Buntinx, Coulter, Craig \&Reeve, 2002).

Following the difficulties facing by pupils with intellectual impairment in learning, in 2008 the government of Tanzania introduced syllabi for pupils with intellectual impairment. The syllabi comprised of subjects such as mathematics, upbringing, health education, communication skills and psychomotor and vocational skills (URT, 2008). The curriculum for pupils with intellectual impairment was prepared to specifically reduce the following: difficulties in learning within and outside the school environment, difficulties in everyday living, difficulties in communication, and delay in developmental stages. The question that arises is whether pupils with autism and intellectual impairment in special and inclusive classrooms in Tanzania perform well academically. It is against this background that this study made an attempt to assess the academic performance of pupils with autism and intellectual impairment in special and inclusive schools in Tanzania.

\subsection{Literature review in brief}

Pupils with autism and intellectual impairment generally have poor performance in academic tasks and face cognitive and learning problems. Cognitive failures include absent-mindedness, memory-related problem, unintentional mistakes and not remembering the names (Wallace, 2004). Several studies (such as, Odom et al., 2010; Asonitou, Koutsouki, Kourtessis \& Charitou, 2012) indicate a positive correlation between cognitive failures and task performance. These studies determined that pupils with autism and intellectual impairment are faced with significant problems in cognitive functions and lower scores in attention and learning (reading, writing, and spelling) compared with their normal peers.

Following the learning difficulties facing by pupils with autism and intellectual impairment in learning, the teaching and learning are prepared to specifically solve the following issues: difficulties in learning within and outside the school environment, difficulties in everyday living, difficulties in communication, and delay in developmental stages. As inclusive education is to be practiced in all schools, it is not possible to re-train all the teachers by sending them to teacher colleges (Mnyanyi, 2014). As such in Tanzania, pupils with related special needs (such as pupils with autism and those with intellectual impairment) are taught in the same classrooms as a means to solve expertise challenges.

The primary education in Tanzania has four main objectives. The first objective is to provide pupils with autism and pupils with intellectual impairment with opportunities to recognize themselves and their environment The second one is to mold the character of the child and enable him/her to acquire acceptable norms of social conduct and behavior. The third is to encourage and promote the pupils with autism and pupils with intellectual impairment acquire skills for self-reliant life. The fourth is to provide pupils with autism and pupils with intellectual impairment with opportunities to acquire and develop reading, writing, and numerical skills. The main subjects in the curriculum are mathematics, caring, health skills, communication skills and psychomotor and vocational skills (URT, 2008). After completing primary school, pupils with autism and pupils with intellectual impairment should have the following competencies: to be able to socialize with people of different status, to live independently, to be employed or self-employed, to develop academically and finally to recognize, preserve and utilize the environment sustainably.

In order to enable pupils with autism and intellectual impairment learn effectively, teachers are advised to utilize various strategies/activities in teaching/learning the respective topics. The strategies suggested in the curriculum are those which actively involve the learner in the learning process. Some of the strategies are demonstration, games, songs, excursion, role play, questions and answers, project work and motivations (Stichter \& Conroy, 2006; URT, 2008). It is important to look into the implementation and relevance of the curriculum for pupils with autism and pupils with intellectual impairment so as to look into its practicability and way forward.

Several studies have dealt with academic performance of pupils with autism and intellectual impairment. Saint-Laurent, Fournier and Lessard (1993) studied on efficacy of three programs for elementary schools with moderate mental retardation involving forty-one students with intellectual handicaps ( 25 boys and 16 girls). The study found no significant differences in academic outcomes for students with moderate developmental disabilities in inclusive, community-based, or traditionally segregated classrooms. These researchers concluded that integration proved to be advantageous for social and behavioural outcomes and that it provided academic, functional, and basic skills instruction that was equal to that provided in more segregated settings.

Two studies investigated numerical estimation skills in autism, both targeting the exact number system. The first one by Jarrold and Russell (1997) investigated counting abilities and possible implications for central coherence theory in United States of America. This was done by investigating whether pupils with autism would 
rapidly and automatically enumerate a number of dots presented in a canonical form or counts each dot individually to obtain the total. The study found that pupils with autism showed less benefit than comparison children in counting dot stimuli presented in canonical (dots on dice) than non-canonical (distributed randomly) form, and used a less efficient dot-by-dot counting strategy. The second study by Gagnon, Mottron, Bherer and Joanette (2004) examined the hypothesis of superior qualification abilities of persons with high functioning autism in Canada. Findings showed that, when asked to judge numerosities between 2 and 9 (e.g., "how many squares are on the screen?"), persons with autism seemed to show evidence of a smaller range than non-autistic persons, although the groups were not compared statistically. It was also revealed no effect of local and global bias of stimuli presentation in the two groups' performance, and no superior quantification abilities in high functioning autism participants.

Wetherby, Prizant and Schuler (1997) studied on enhancing language and communication to pupils with autism. Enhancing language and communication skills of pupils with autism is one of the greatest challenges for teachers and families. This is due to the fact that, the development of language and communicative abilities is a major challenge faced by persons with autism. Most people are unaware of the complexity of normal communication because children develop these skills automatically, usually by the age of three or four. The study found that many pupils with autism spectrum disorder did not develop the skills they need for spontaneous communication, and must, therefore, be taught these. Helping pupils with autism spectrum disorder develop communication skills-so that they can express their wants and needs, interact socially, share information, express emotions, and protest or escape aversive situations, is a priority.

Another study by Argyropoulou and Papoudi (2012) examined the effectiveness of intensive interaction during interactive play between a preschool boy with autism and his teacher and, as a consequence, improve the social interaction between the boy and a non-autistic girl in an inclusive class in Greece. Results indicated significant improvement and post-training maintenance in the social interaction of the two children. Findings also added that pre-school children, when involved in more interactions in scheduled activities, are the ones they usually prefer or when the material is predictable and familiar. Hodgdon (1995) studied on solving socialbehavioral problems through the use of visually supported communication found that the use visual input to aid comprehension of oral speech. Findings revealed that visual supports are helping children who do not have conventional communication systems to become more able communication partners. Accompanying spoken language with relevant objects, pictures, and other visual supports can help with comprehension. Experienced teachers of pupils with autism suggest the use of photographs support understanding of the content of oral language communication. Interestingly, many pupils with autism use reading to support oral comprehension rather than the expected reverse of using oral language to support reading, making reading instruction even more significant for these students.

\section{Methods and Procedures 3.1Design}

This study adopted mixed method research approach. The approach was also considered useful in carrying out in-depth investigation in order to obtain detailed information about academic performance of pupils with autism and intellectual impairment in inclusive primary schools. The study was conducted in Dar es Salaam and Mbeya regions, focusing on special and inclusive schools enrolling pupils with autism and intellectual impairment. The two regions were purposefully selected for this study because of their nature and socio-economic differences. The regions represent differences in communities, both at economic and cultural orientations levels. It was also evident that the two regions, given their economical, social and educational status (URT, 2008a; URT, 2012).Purposive sampling was used to select primary schools and pupils with autism and intellectual impairment. The sample size comprised50 pupils with autism and intellectual impairment. These pupils were selected from five primary schools, three primary schools located in Dar es Salaam and two primary schools located in Mbeya regions.

\subsection{Instruments}

The data were collected through pupil's assessment tool (pupil's test). This tool enabled the researcher to be acquainted with the nature of the learning for pupils with autism and intellectual impairment. The assessment tool was used to obtain data on the pupil's academic performance in selected skills (such as number skills, communication skills, and vocational skills) of identified pupils in level two of the syllabus for pupils with intellectual impairment. Researchers observed on how pupils participate in the learning process and determined the variability in their academic performance in the selected academic tasks.

\subsection{Data Analysis Procedure}

Data were analysed descriptively (percentages, mean scores and standard deviations). The presentation of these data aimed at providing comparison of the academic performance of the pupils. To aid interpretation of the 
operational tasks, the study adopted interpretive scale, that; 1 represent $0-10 \%$ (means completely failed); 2 represent $11-50 \%$ (partially performed); and 3 represent $51-100 \%$ (excellent performance). The paired t-test was used to analyse the counting skills of the pupils, while the differences in their academic performance was established by the use of chi-square test.

\section{Findings and Discussion}

In order to compare academic performance between pupils with autism and those with intellectual impairment learning tasks were designed and administered to suit number skills, communication skills and vocational skills.

\subsection{Academic Performance of Number Skills \\ 4.1.1Counting skills}

Pupils with autism and intellectual impairment were assigned to count 1 to 30 . For this task, the researchers displayed pictures of various things and pictorial representation of things. These comprised pictures of 5 butterflies, 11 goats, 13 shoes, 19 houses and 21 cats. The performance of counting things was categorized in three different intervals in varying levels of difficulty, including an interval that identifies learners who failed to perform the assignment. Table 1 presents the academic performance of the pupils involved in the assignment.

Table 1: Academic Performance in Counting Things (1-30)

\begin{tabular}{lccc}
\hline \multirow{2}{*}{ Ability to count } & \multicolumn{2}{c}{ Pupils Disability } & \multirow{2}{*}{ Total (\%) } \\
\cline { 2 - 3 } & Autism & Intellectual Impairment & 100.00 \\
\hline to $10(\mathrm{n}=16)$ & $81.25 \%$ & $18.75 \%$ & 100.00 \\
1 to $20(\mathrm{n}=21)$ & $33.33 \%$ & $66.67 \%$ & 100.00 \\
1 to $30(\mathrm{n}=12)$ & $0.00 \%$ & $100.00 \%$ & 100.00 \\
None $(\mathrm{n}=1)$ & $100.00 \%$ & $0.00 \%$ & 100.00 \\
Total $(N=50)$ & $42.00 \%$ & $58.00 \%$ & \\
\hline
\end{tabular}

$\left(X^{2}=21.0, d f=3, p=0.05\right)$

Findings show that more than half of the pupils with autism were able to count things 1-10 and the remaining counted only up to 20, while most of the pupils with intellectual impairment managed to count 1 to 30 of the real things given for the assignment. Pupils with intellectual impairment managed to perform tasks in all categories but one pupil with autism failed to attempt any of the tasks given. The association of the differences in academic performance between pupils with autism and intellectual impairment was statistically significant $\left(x^{2}=21.0, d f=3, p=0.05\right)$; suggesting that pupils with intellectual impairment performed higher in count things from one to thirty compared to those with autism. Findings concur with Jarrold and Russell (1997) who researched the ability of pupils with autism in counting dot in canonical (dots on dice) and non-canonical (distributed randomly) form. Pupils with autism used a less efficient dot-by-dot counting strategy.

\subsubsection{Number recognition}

In assessing academic performance of pupils to recognize numbers, cards with numbers from 1 to 30 were displayed for the pupils to recognize them. Each pupil with autism and intellectual impairment was required to recognise numbers shown in the cards. Each pupil was given at least ten minutes (time for the assignment depended on pupil's competence) to accomplish the assignment. The findings are presented in Table 2.

Table 2: Recorded Academic Performances in Number Recognition (1 to 30)

\begin{tabular}{lccc}
\hline \multirow{2}{*}{ Number rows } & \multicolumn{2}{c}{ Pupils disability } & \multirow{2}{*}{ Total (\%) } \\
\cline { 2 - 3 } & Autism & Intellectual impairment & 100.00 \\
Between 1-10 $(\mathrm{n}=19)$ & $57.89 \%$ & $42.11 \%$ & 100.00 \\
Between 11-20 $(\mathrm{n}=18)$ & $22.22 \%$ & $77.78 \%$ & 100.00 \\
Between 21-30 $(\mathrm{n}=7)$ & $0.00 \%$ & $100.00 \%$ & 100.00 \\
None $(\mathrm{n}=6)$ & $100.00 \%$ & $0.00 \%$ & 100.00 \\
Total $(N=50)$ & $42.00 \%$ & $58.00 \%$ & \\
\hline
\end{tabular}

$\left(X^{2}=18.27, d f=3, p=0.05\right)$

Table 2 shows that pupils with autism who managed to identity numbers displayed to them fall under category one and two of the assignment which are below 20. More than half of pupils with autism recognised numbers, 1-10 and other few of them recognised 11-20. Majority of the pupils with intellectual impairment managed to recognise numbers 11-20 and all of those recognised numbers 21-30 were pupils with intellectual impairment, while none of the pupils with autism managed to perform the third category (21-30) of this assignment. For those who failed to recognise any number given for the assignment were pupils with autism. Similar findings observed by Gagnon, Mottron, Bherer and Joanette (2004) who assessed the ability of categories of adolescents with disabilities to judge numerosities between 2 and 9 by indicating squares are on the screen. Adolescents with autism performed lower comparing to non-autistic adolescents.

These findings reveal that pupils with intellectual impairment were more capable in recognition of numbers comparing to pupils with autism. The variation in pupils' academic performance on number recognition was 
statistically significant $\left(x^{2}=18.27, d f=3, p=0.05\right)$. This suggests that pupils' ability to recognise numbers varied. While most pupils with autism were capable in recognising numbers 1-10 and very few exceeded up to 11-20 category; pupils with intellectual impairment were capable to work with second and third categories (i.e. 11-30). Apart from that, findings from this assignment present an important fact about pupils with autism, that some of the pupils in this group managed to recognize the number but failed to count any of the real things presented to them.

\subsubsection{Mathematical operations}

This section presents the data on pupils' abilities of mathematical operations. In order to assess the abilities, pupils were provided with simple mathematical tasks involving numbers that ranged from 1 to 30 . With the aid of activity-based assignments, the pupils were assigned to perform addition, subtraction, multiplication and division of simple arithmetic. The findings are presented in Table 3.

Table 3: Performance of Pupils with Autism and Intellectual Impairment in Mathematical Operations

\begin{tabular}{lcccc}
\hline \multirow{2}{*}{ Operation } & \multicolumn{2}{c|}{ Autism $(\mathrm{n}=21)$} & \multicolumn{2}{c}{ Intellectual impairment $(\mathrm{n}=29)$} \\
\cline { 2 - 5 } & $M$ & $S D$ & $M$ & $S D$ \\
\hline Addition & 1.24 & .44 & 1.34 & .48 \\
Subtraction & 1.05 & .22 & 1.41 & .50
\end{tabular}

$[t=0.29, p=0.05]$

Key: $1=(0-10) \% ; 2=(11-50) \% ; 3=(51-100) \%$

Table 3 indicates that in addition task pupils with intellectual impairment performed slightly higher than pupils with autism On the other hand, there was a greater variation in the subtraction task where the mean performance of the pupils with intellectual impairment was higher $(M=1.41, S D=.50)$ compared to those pupils with autism who attained lower performance $(M=1.05, S D=.22)$. However, this pupils' differential performance in both operations were statistically not significant $(t=0.29, p=0.05)$. This suggests that pupils' academic performance on these tasks were almost equal. Similarly, Saint-Laurent, Fournier and Lessard (1993) found no significant differences in academic outcomes for students with moderate developmental disabilities in inclusive, community-based, or traditionally segregated classrooms. Such findings concluded that integration proved to be advantageous for social and behaviouraloutcomes and that it provided academic, functional, and basic skills instruction that was equal to that provided in more segregated settings.

\subsection{Academic Performance in Communication Skills}

The study also sought to assess communication skills with the aid of some selected tasks including brief short expressions and storytelling.

\subsubsection{Short Expression}

Under this item, the aim was to assess the ability of pupils communicating on issues of their day-to-day situations. In this assignment, special education teachers were involved in asking pupils to introduce themselves, name their school, teachers and friends. Findings for this task are presented in Table 4.

Table 4: Capability of Pupils with Autism and Intellectual Impairment in Short Expressions

\begin{tabular}{lcccc}
\hline \multirow{2}{*}{ Task } & \multicolumn{2}{c}{ Autism $(\mathrm{n}=21)$} & \multicolumn{2}{c}{ Intellectual impairment $(\mathrm{n}=29)$} \\
\cline { 2 - 5 } & $M$ & $S D$ & $M$ & $S D$ \\
\hline Self introduction & 1.48 & .51 & 1.07 & .26 \\
Naming of parents & 1.81 & .40 & 1.59 & .50 \\
Naming school & 1.76 & .44 & 1.17 & .38 \\
Name of a teacher & 1.76 & .44 & 1.21 & .41 \\
Name of friend & 1.67 & .48 & 1.45 & .51
\end{tabular}

$[t=0.008, p=0.05]$

Key: $1=$ High performance; $2=$ Low performance

Table 4 indicates the pupils' variations in the abilities to express themselves. On self introduction the findings indicate that pupils with intellectual impairment performed high $(M=1.07, S D=.26)$ than those with autism $(M=1.48, S D=.51)$. On naming the parents, although the task was almost difficult for both categories of pupils; but those with autism performed lower $(M=1.81, S D=.40)$ in naming their parents compared to those pupils with intellectual impairment $(M=1.59, S D=.50)$. This task was given to pupils in a common way similar to when someone need to familiarise to other people usually their first and surnames.

For the task that required the pupils to name their schools and teachers, the capabilities were equally distributed despite the differences in the pupils' ability on separate tasks. In naming a school and a teacher pupils with autism scored lower $(M=1.76, S D=.44)$ compared to pupils with intellectual impairment although variations among pupils with autism were relatively high. Pupils with intellectual impairment scored higher in naming a school and a teacher $(M=1.17$ and $M=1.21$ respectively). In naming a friend lower academic performance was recorded to those pupils with autism $(M=1.67, S D=.48)$ compared to those with intellectual impairment $(M=1.45$, $S D=.51)$. 
Moreover, findings indicate that the difference in the pupils' academic performance to short expressions were statistically significant $(t=0.008, p=0.05)$; which reveal that the pupils abilities on self introduction, naming parents, schools, teachers and friends were significantly different. Findings reveal that some pupils with autism performed low in communication tasks which may signify a lack of social skills and competencies; presumably, they were not frequently exposed to socialize more with other pupils. Pupils with intellectual impairment in inclusive schools recorded minimum variations due to the fact that being in inclusive schools had helped them to basic communication skills through interactions with pupils without disabilities who provided them with cues, prompts and consequences.

Pupils with autism mostly demonstrated antisocial behaviour, especially when attempting to communicate with others, particularly when assigned to work with things. Pupils with autism had difficulty in generalizing learned speech to new situations and people, due to their overly selective attention and had the tendency to respond to only a limited number of cues. Wetherby, Prizant and Schuler (1997) found similar challenges that many pupils with autism have not developed the skills they need for spontaneous communication. Communication skills of pupils with autism are one of the greatest challenges for teachers and families. Most people are unaware of the complexity of normal communication because children develop these skills automatically, usually by the age of three or four.

\subsubsection{Telling and listening to stories}

As part of communication skills assessment, a brief story was presented to pupils with autism and intellectual impairment. The pupils were asked to repeat the story, to identify names of the characters and key themes narrated in the study. The findings are presented in Table 5.

Table 5:Performance of Pupils with Autism and Intellectual Impairment in Telling and Listening to Stories

\begin{tabular}{lcccc}
\hline \multirow{2}{*}{ Task } & \multicolumn{2}{c}{ Autism } & \multicolumn{2}{c}{ Intellectual impairment } \\
\cline { 2 - 5 } & $M$ & $S D$ & $M$ & $S D$ \\
\hline Reproducing a story & 1.43 & .51 & 1.66 & .48 \\
Naming people & 1.33 & .48 & 1.72 & .45 \\
Recall issues & 1.14 & .36 & 1.59 & .57
\end{tabular}

$[t=0.013, p=0.05]$

Key: $1=$ Failed; $2=$ Average performance; $3=$ Higher performance

Table 5 shows that in this assignment of telling and listening stories pupils with intellectual impairment recorded a higher performance in almost all tasks assigned compared to those with autism. Findings indicate that although pupils with autism underperformed in almost all tasks, but the worst performance $(M=1.14, S D=.36)$ was recorded on the task related to recall of issues. Generally, the differences in the pupils' ability to tell and listen to stories were significant $(t=0.013, p=0.05)$. This however, indicates that although the relationship in the pupils' academic performance was inversely scored but those with intellectual impairment performed higher than pupils with autism in telling and listening to stories. These findings concur with Hodgdon (1995) and Argyropoulou and Papoudi (2012) who added that social behaviour of a pupil with autism, make difficult for them to have intensive interaction and initiate communication with a peer play partner.

\subsection{Academic performance in Vocational Skills}

The third task was geared towards establishing the extent to which performance of pupils with autism and intellectual impairment differs in the recognition of vegetables, distinguishing picture and building puzzles.

\subsubsection{Vegetable recognition and distinguishing pictures}

For this task, varieties of vegetables were displayed and the pupils with autism and intellectual impairment were asked to name them. These types of vegetables were familiar to pupils and were from the surrounding (these included tomatoes, lady finger, capsicum and onion) and easily found in the nearby markets, if not available in their family gardens. Findings are presented in Table 6.

Table 6: Academic Performance of Pupils with Autism and Intellectual Impairment in Vegetable Recognition and Distinguishing Pictures

\begin{tabular}{lcccc}
\hline \multirow{2}{*}{ Task } & \multicolumn{2}{c|}{ Autism } & \multicolumn{2}{c}{ Intellectual impairment } \\
\cline { 2 - 5 } & $M$ & $S D$ & $M$ & $S D$ \\
\hline Vegetable recognition & 1.86 & .36 & 2.28 & .59 \\
Distinguish pictures & 1.90 & .54 & 2.66 & .55
\end{tabular}

Key: $1=0.13, p=0.05]$

Table 6 indicates the pupils' scores in the recognition of vegetables and distinguishes pictures. Although the mean score slightly varied despite the differences in the pupils' disability, but those with intellectual impairment attained a higher performance compared to those with autism in both categories. Nevertheless, pupils with autism had almost similar ability $(M=1.86$ and $M=1.90)$. Pupils with intellectual impairment performed higher 
$(M=2.28)$. However, the deviation was high among pupils with intellectual impairment in both tasks assigned. However, this difference was not significant $(t=0.13, p=0.05)$; suggesting that academic performance of pupils with autism and those with intellectual impairment were almost similar.

\subsubsection{Building puzzle}

The study aimed to examine academic performance of pupils with autism and intellectual impairment in playing with puzzles and build complete image of tomatoes and zebra. Pupils were assigned to play puzzle games and rearrange the blocks to display pictures of tomatoes and zebra. This task involved only the pupils with autism and intellectual impairment who showed awareness of participating in this assignment. Table 7 presents the findings.

Table 7:Performance of Pupils with Autism and Intellectual Impairment on Tomato and Zebra Puzzles

\begin{tabular}{lcccc}
\hline \multirow{2}{*}{ Task } & \multicolumn{2}{c|}{ Autism } & \multicolumn{2}{c}{ Intellectual impairment } \\
\cline { 2 - 5 } & $M$ & $S D$ & $M$ & $S D$ \\
\hline Tomato puzzle & 1.86 & .65 & 2.24 & .69 \\
Zebra puzle & 1.90 & .54 & 2.41 & .63 \\
{$[\mathbf{t = 0 . 1 0}, \mathbf{p}=\mathbf{0 . 0 5}]$} & & & &
\end{tabular}

Key: $1=$ Failed; $2=$ Average performance; $3=$ Higher performance

Table 7 indicates that more pupils with autism had average performance in both tasks $(M=1.86$ and $M=1.90)$. However, the standard deviation recorded high $(S D=.65)$ on tomato puzzle, meaning that few pupils with autism had average performance on the task. The pupils with intellectual impairment attained higher performance in almost all tasks assigned compared to those with autism. Their mean score recorded higher on tomato puzzle $(M=2.24, S D=0.69)$ and on zebra puzzle $(M=2.41, S D=.63)$.

In the light of the findings, pupils managed to work easily with real things which are recognizable in other tasks. In zebra puzzle pupils with autism demonstrated similar performance as in tomato puzzle, that majority of the pupils with autism also performed partially in this assignment. In this puzzle task the difference in academic performance was also not statistically significant $(t=0.10, p=0.05)$; meaning that academic performance for pupils in both categories were similar.

Findings on the performance of pupils with autism and intellectual impairment vividly demarcate variations in their academic performance. On one hand, in most of the assignments pupils with autism performed simple tasks and failed to address much more demanding tasks (such as addition and subtraction). Other the other hand, pupils with intellectual impairment managed to perform all simple tasks and few of them showed some managed to perform well on higher order assignments. These findings are contrary to Blackorby, Chorost, Garza and Guzman (2004) who reported that while among the measures of academic performance for pupils considered having Attention Deficit Disorder/ADHD, independent of other disabilities, relates only to lower grades.

\section{Conclusion}

In the light of the findings from the study, it is concluded that: firstly, pupils with intellectual impairment performed highly comparing to pupils with autism, it was noted that both managed to perform low demanding academic tasks. Therefore, there is a lot to be done to enable them to acquire all competencies as outlined in the syllabi used for pupils with autism and intellectual impairment. Secondly, it was obviously noted that learning between pupils with autism and pupils with intellectual impairment and pupils without disabilities were different in both academic and as well as general educational practices and management. Despite the difficulties in establishing appropriate parameters for them in comparing all academically selected tasks, but failure to acquire proper facilitation and teaching and learning approaches pupils with autism and pupils with intellectual impairment would hardly learn efficiently. This challenge remains critical in enabling provision of quality primary education for pupils with autism and pupils with intellectual impairment in Tanzania.

\section{Recommendations}

Basing on the findings of this study, the following recommendations are made. Firstly, the government through Ministry of Education, Science and Technology (MoEST) should allocate sufficient funds to ensure that the teaching and learning processes for pupils with autism and intellectual impairment is improved. This will definitely support them to acquire competencies that would enable them to live self-reliant and independent life after the primary education cycle.

Secondly, it is recommended that the curriculum for primary education should be reviewed. This would enable pupils with disabilities to acquire curriculum relevant for their educational needs. Nevertheless, serious efforts should be taken by stakeholders in education including the government through the Ministry of Education, Science and Technology, community, parents for pupils with autism and intellectual impairment to ensure that these pupils learn effectively all subjects as prescribed in their curriculum. Thirdly, it is recommended that more special education teachers should be deployed in inclusive primary schools that will be available to serve for all pupils with special education needs in Tanzania. 


\section{References}

Argyropoulou, Z.,\&Papoudi, D. (2012). The training of a child with autism in a Greek preschool inclusive class through intensive interaction: A case study. European Journal of Special Needs Education, 27(1), 99-114.

Asonitou, K., Koutsouki, D., Kourtessis, T., \& Charitou, S. (2012). Motor and cognitive performance differences between children with and without developmental coordination disorder DCD. Research in Developmental Disabilities, 33, 996-1005.

Blackorby, J., Chorost, M., Garza, N.,\& Guzman, A. (2004).The academic performance of elementary and middle school students with disabilities.Special Education Elementary Longitudinal Study [SEELS]

Bloom, D., Canning, D.,\& Chan, K. (2006).Higher Education and Economic Development in Africa, Havard University.

Cole, D. A., \& Meyer, L. H. (1991). Social integration and severe disabilities: A longitudinal analysis of child outcomes. Journal of Special Education, 25, 340-351.

Cole , C. M., Waldron, N.,\&Majd , M . (2004). Academic progress of students across inclusive and traditional settings.Mental Retardation, 42, 136-144.

Dessemontet, R. S. \& Bless, G. (2013).The impact of including children with intellectual disability in general education classrooms on the academic achievement of their low-, average-, and high-achieving peers.Journal of Intellectual \& Developmental Disability, 38(1), 23-30.

Gagnon, L., Mottron, L., Bherer, L., \&Joanette, Y. (2004). Quantification judgment in high-functioning autism: Superior or different? Journal of Autism and Developmental Disorders, 34, 679-689.

Hart, J. E., \&Whalon, K. J. (2011). Creating social opportunities for students with autism spectrum disorder in inclusive settings. Intervention in School and Clinic, 46(5), 273-279.

Hodgdon, L. A. (1995). Visual Strategies for Improving Communication: Practical supports for school and home.Troy, MI: Quirk Roberts

Jarrold, C., \& Russell, J. (1997). Counting abilities in autism: Possible implications for central coherence theory. Journal of Autism and Developmental Disorders, 27, 25-37.

Luckasson, R., Borthwick-Duffy, S., Buntinx, W. H. E., Coulter, D. L., Craig, E. M., Reeve, A. (2002). Mental retardation: Definition, classification, and systems of supports $\left(10^{\text {th }} \mathrm{ed}\right.$.). Washington, DC: AAMR.

Mnyanyi, C. B. F. (2014). Changing Teachers' Practices in Regular Schools Enrolling Children with Visual Impairment. An Action Research Project in Tanzania.

National Autistic Center-Kenya. (2009). Characteristics of Autistic Children. Retrieved from http://www.sepkenya.com/brochures/autism.p65.pdf

Odom, S., Boyd, B. A., Hall, L. J., \& Hume, K. (2010). Evaluation of comprehensive treatment models for individuals with autism spectrum disorders. Journal of Autism and Developmental Disorders, 40, 425-436.

Odom, S. L., Brown, W. H., Frey, T., Karasu, N., Smith-Canter, L., \& Strain. P. S. (2003). Evidence-based practices for young children with autism: Contributions for single-case design research. Focus on Autism and Other Developmental Disabilities, 18, 166-175.

Saint-Laurent, L., Fournier, A. L., \&Lessard, J. C. (1993).Efficacy of three programs for elementary school students with moderate mental retardation.Education and Training in Mental Retardation and Developmental Disabilities, 28, 333-348.

Sicile-Kira, C. (2004).Autism Spectrum Disorders. New York: Penguin.

Stichter, J. P., \& Conroy, M. A. (2006). How to teach social skills and plan for peer social interactions. Series on Autism Spectrum Disorders. Austin, TX: Pro-Ed.

Tungaraza, F. D. (1994). The development and history of special education in Tanzania.International Journal of Disability, Development and Education, 41(3), 213-222.

United Nations. (2007). Convention of the rights of persons with disabilities. UN: New York.

URT. (2006). Education Sector Development Programme (ESDP): Education Sector Review. Dar es Salaam: Ministry of Education and Vocational Training.

URT. (2008). Syllabi for Pupils with Mental Disabilities. Dar es Salaam: Ministry of Education and Vocational Training

URT. (2008a). The Development of Education: National Report of the United Republic of Tanzania. Dar es Salaam: Ministry of Education and Vocational Training

URT.(2012).Basic Education Statistics in Tanzania 2008-2012.National Data. Dar es Salaam:Government Printer.

Wallace, J. C. (2004). Confirmatory factor analysis of the cognitive failures questionnaire: Evidence for dimensionality and construct validity. Personality and Individual Differences, 37, 307-324.

Wetherby, A. M., Prizant, B. M., \& Schuler, A. L. (1997). Enhancing language and communication: Theoretical foundations. In D. Cohen \& F. Volkmar (Eds.), Handbook of autism and pervasive developmental disorders $\left(2^{\text {nd }}\right.$ ed.). New York: Wiley.

Woods, E. (2007). Education for all global report 2008: Education for all by 2015: Will we make it. Paris: UNESCO. 